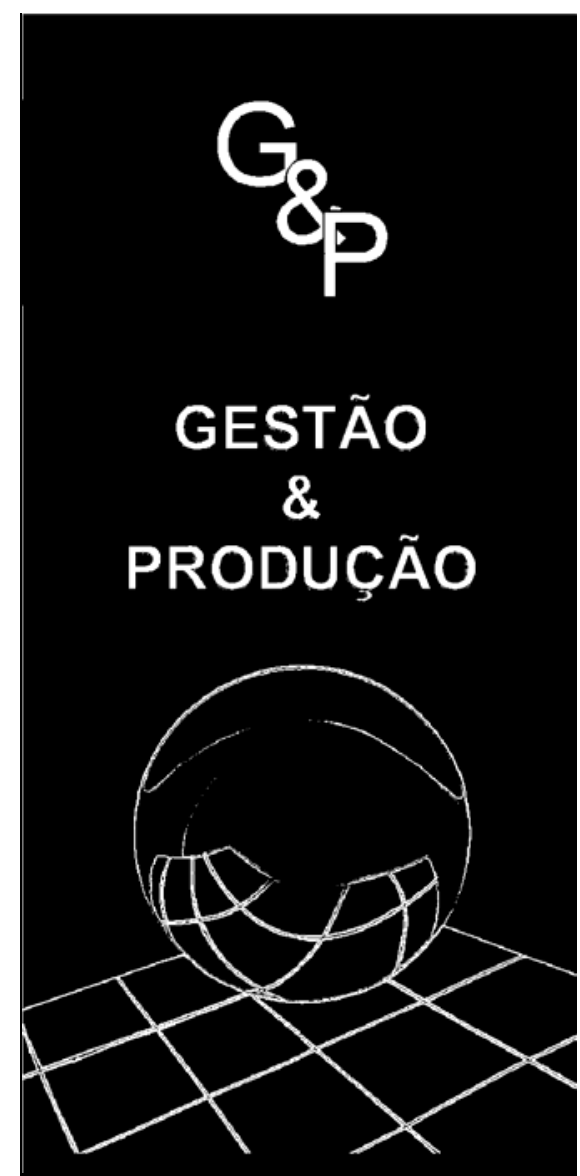

v.3, n.1, p. 70-85, abr. 1996

\section{FATORES E PROCEDIMENTOS DETERMINANTES DA QUALIDADE DO PROJETO DE PRODUTOS VISANDO A COMPETITIVIDADE}

Luiz Airton Consalter, M.Eng.

Faculdade de Engenharia - Depto. de Eng. Mecânica - UPF 99.001-970 - Passo Fundo / RS

\title{
Resumo
}

A influência da qualidade do projeto sobre a competitividade de um produto se exerce em todos os estágios do seu ciclo de vida. Este artigo apresenta uma maneira sistematizada de relacionar a qualidade do projeto do produto e a competitividade das empresas por meio dos fatores influentes nessa relação, procurando salientar sua importância. Os diferentes procedimentos usados para agregar qualidade são abordados de maneira que se possa orientar as empresas na organização de suas equipes de projeto. A fase conceitual do projeto é destacada como o foco dos esforços de qualificação do produto.

\section{Palavras-chave: projeto do produto, qualidade, competitividade.}

\section{Introdução}

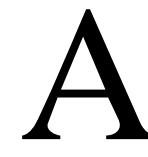

qualidade no projeto do produto, visando a competitividade, é um tema suficientemente amplo para que qualquer tentativa clássica de conceituação fique subjetiva e evasiva. Assim, é mais proveitoso tratar o assunto de maneira a sistematizar e esclarecer os fatores e procedimentos que levam à qualidade do projeto do produto.

inserida uma série de procedimentos para a
A competitividade mundial encontra-se em um nível tão acentuado, em diversos segmentos, que a qualidade do projeto do produto, em todos os estágios, e principalmente na fase conceitual, precisa ser perseguida utilizando-se todos os recursos obteníveis. A vantagem competitiva reside em detalhes qualitativos do produto e do processo de projeto, e por trás disso está busca da qualidade. Sob esse ponto de vista, 
a qualidade do projeto do produto para a competitividade não pode ser vista apenas a partir do resultado de custos ou de características técnicas e funcionais do produto, mas sim a partir das necessidades globais dos clientes internos, intermediários e externos.

O objetivo do presente artigo é elucidar a diversidade de fatores envolvidos na qualidade do projeto do produto, bem como sua relevância para a competitividade e, paralelamente, delinear procedimentos técnicos e administrativos no sentido de orientar as empresas na tomada de decisões.

A quantidade relativamente grande de fatores e procedimentos que levam à qualidade do projeto do produto, associada à variedade de metodologias e recursos tecnológicos disponíveis, dificulta a organização das empresas para que se tornem ou se mantenham competitivas; como esta condição se torna um requisito de mercado cada vez mais indispensável, é fundamental a sistematização dos procedimentos das equipes de projetos para a incorporação de qualidade ao produto.

\section{Panorama da Competitividade do Produto}

\subsection{Competitividade do produto - É melhor sistematizar do que conceituar}

$\mathrm{A}$

habilidade de atrair e satisfazer clientes é a forma mais genérica de referenciar a competitividade do produto de uma empresa, obviamente, em relação aos seus concorrentes. Esta forma de conceituar a competitividade não é suficiente para o entendimento do que deve ser levado em consideração num produto para que procedimentos e ações possam ser adotados de maneira que uma empresa possa tornar-se mais competitiva; assim, é preciso ser mais sistemático do que conceitual ao tratar da competitividade do produto. Neste sentido, pode-se dizer que a performance do desenvolvimento do produto, resultante da sua organização e gerenciamento, em paralelo à estratégia mercadológica da empresa, é considerada, juntamente com outros fatores, o aspecto determinante da competitividade, conforme esquematizado na figura 1 (CLARK \& FUJIMOTO, 1991).

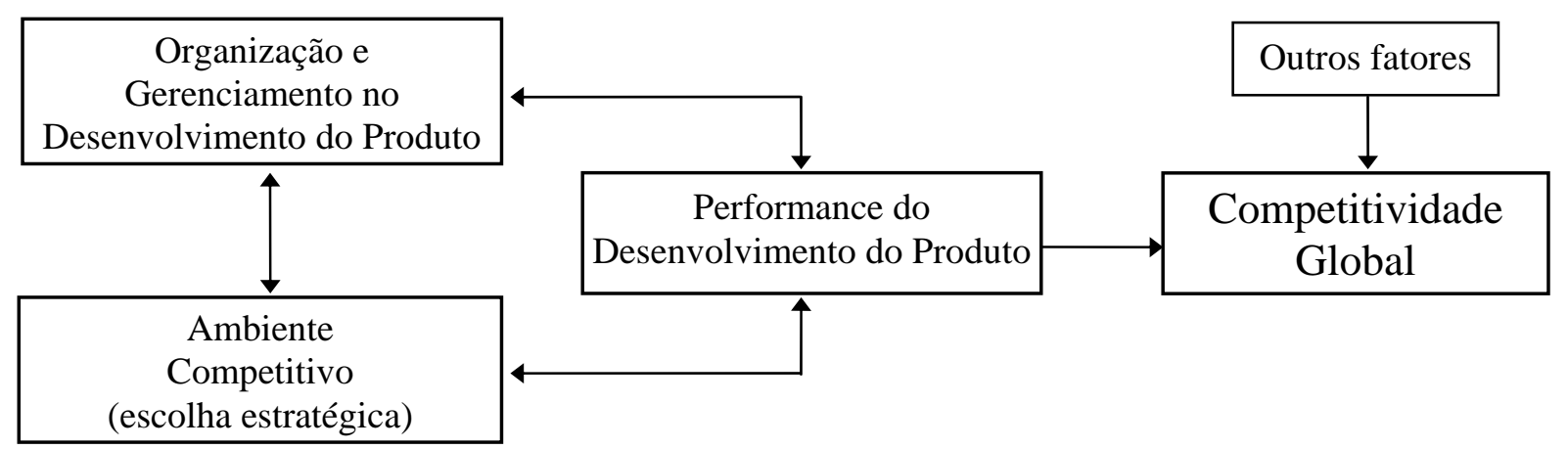

FIGURA 1 - Fatores da performance do desenvolvimento do produto

No entanto, as colocações acima, quanto à performance do desenvolvimento do produto, não deixam suficientemente explícitos os meios de atingir a competitividade. Para isso é necessário conhecer com maiores detalhes os fatores, os procedimen- tos e os comportamentos que determinam essa performance, bem como consider todos os “outros fatores” mencionados na figura 1 , pois não são fatores de importância secundária. O conhecimento e a consideração de todos os fatores envolvidos no projeto do 
produto, embora não constituam tarefa simples, situam bem os aspectos dos quais depende a competitividade de um produto.
Desde que a qualidade em cada fator seja considerada, a competitividade da empresa como um todo será alcançada.

\subsection{Rivalidade de produtos}

A globalização da economia a partir dos anos 80 está associada à fragmentação dos mercados, às importações e às mudanças tecnológicas, além dos fatores políticoeconômicos. Com isso, aumentou significativamente a quantidade de competidores habilitados para o mercado internacional. Em decorrência, a competição torna-se mais intensa e, além disso, a concorrência regional está cedendo lugar à competição direta “produto-a-produto” em larga escala; é a chamada rivalidade de produtos. Essa rivalidade passa a ser uma questão de sobrevivência competitiva em vários segmentos de mercado, nos quais empresas de diferentes setores e capacidades são forçadas a competir diretamente para manter suas fatias de mercado.

\subsection{Vantagem competitiva}

Nesta nova conjuntura, a vantagem competitiva passa a nortear as estratégias das empresas; a meta das gerências volta-se para o desenvolvimento mais rápido e eficaz de produtos novos e com melhor qualidade, menor custo e que satisfaçam os clientes. Cabe ressaltar aqui, que o custo representa uma parcela das prioridades competitivas (entre custo, qualidade, desempenho das entregas e flexibilidade) e, que essa parcela isoladamente representa um papel estratégico para as empresas, uma vez que, segundo ALVES et al (1995), a redução do custo propicia ganhos adicionais ou permite a redução dos preços. Considerando que os elementos que compõem o custo são o custo inicial, o custo de operação e o custo de manutenção, e que o comportamento destes é conseqüência do projeto do produto, então o foco da competição passa a ser o desenvolvimento de novos produtos exigindo alta performance no seu desenvolvimento. Temse, assim, no projeto de produto a variável diferenciadora da vantagem competitiva, sendo que o comportamento dessa variável define a competitividade da empresa. É extremamente importante adiantar-se ao concorrente, com produtos diferenciados, sendo que essa diferenciação deve ser buscada na capacidade própria de incorporar qualidade ao projeto do produto.

\subsection{Extensão da competitividade na empresa}

A competitividade não se limita ao uso de novas tecnologias ou da performance do desenvolvimento do produto com base na capacidade de projeto e de produção da empresa, mas requer, sobretudo, visão daqueles que comandam a mudança, habilidade para definir prioridades visando a performance internacional, sensibilidade às necessidades do cliente, liderança no projeto e na manufatura e competência mercadológica.

\subsection{Valores do produto}


para que a empresa considere significativamente este item no desenvolvimento do produto. A figura 2 ilustra a estratégia de "capturar" o consumidor pelo valor do produto, considerando a tríade empresa/concorrente/consumidor. A empresa deve atrair o consumidor incorporando ao produto mais valores do que o seu concorrente possa incorporar. Sobre esses valores influem os seguintes aspectos: função, características, qualidade técnica, preço, disponibilidade e a perda da função qualidade. O objetivo é ganhar a confiança do consumidor, proporcionando valor de destaque ao produto. Isso pode ser conseguido atuando-se convenientemente sobre os setores de marketing, projeto, engenharia, produção, serviços e vendas.

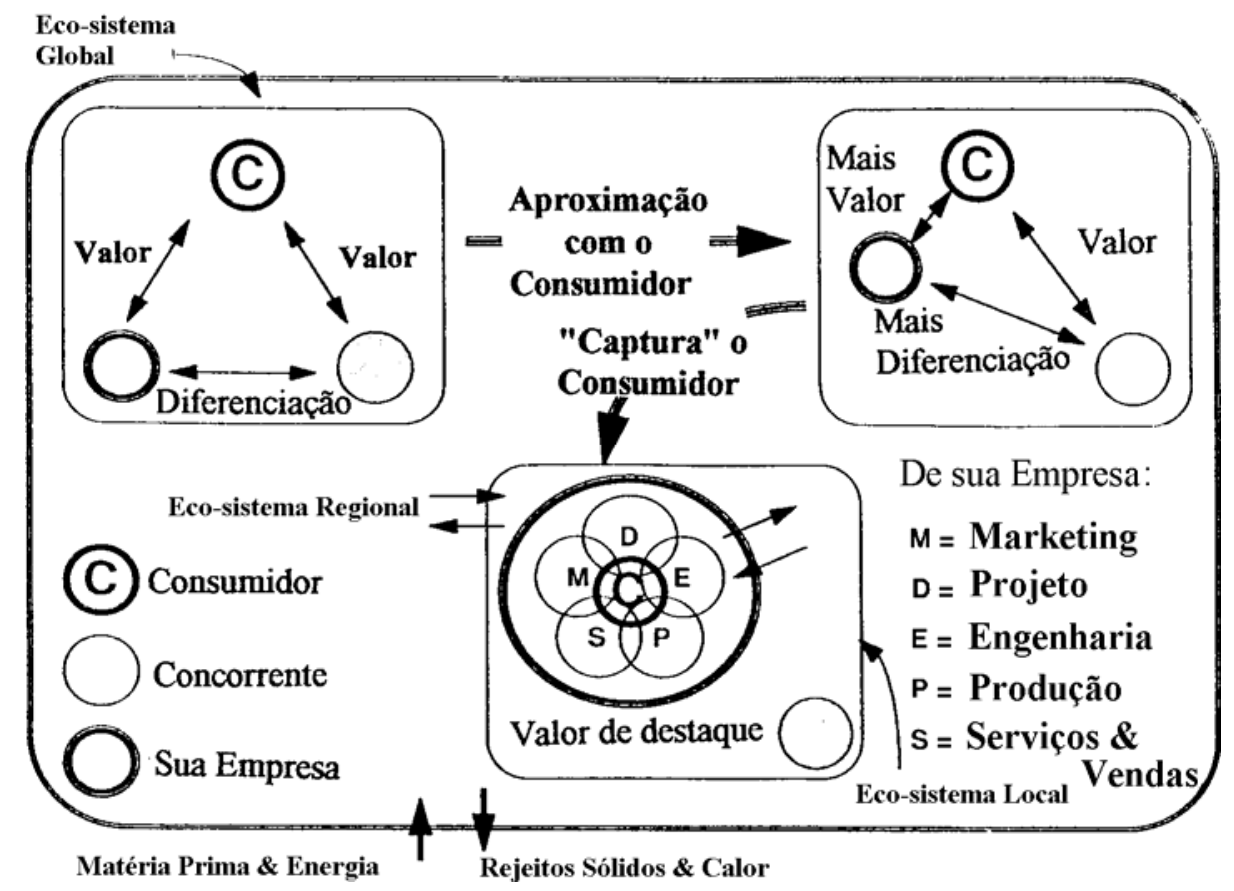

FIGURA 2 - Estratégia competitiva: “Capturar” o consumidor pelo destaque no valor do produto (TIPNIS, 1994)

Segundo SOHLENIUS (1992), a competitividade de um produto é determinada por três valores: qualidade, lead-time e complexidade. Para ser competitivo um produto, deve ter alta qualidade, baixo lead-time e mínima complexidade. Na figura 3 está esquematizada a evolução do projeto do produto visando a competitividade. Considera-se que o desenvolvimento cooperativo deva estar previsto no planejamento estratégico das empresas, pois os consumidores passam, cada vez mais, a avaliar o produto tomando por base todos os pontos de interação com as empresas, em detrimento da avaliação pelo produto isoladamente. Este comportamento é um fator que agrega valor ao produto. 


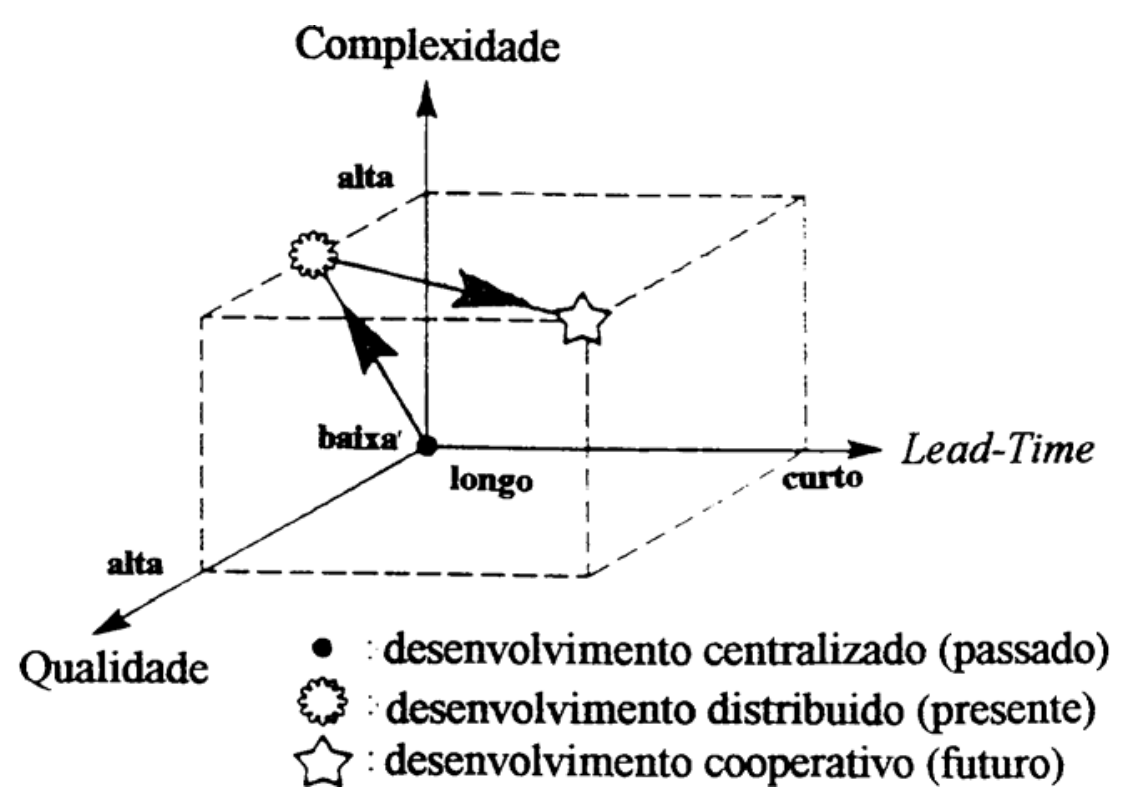

FIGURA 3 - Competitividade do projeto do produto e sua evolução (SOHLENIUS, 1992)

\subsection{Percepção das necessidades do cliente}

Um dos principais problemas no projeto do produto, tipicamente em sua fase conceitual, é a dificuldade de percepção das necessidades do consumidor, para que então sejam traduzidas em decisões de engenharia. Portanto, um desafio para a empresa alcançar a competitividade mediante o seu produto é identificar necessidades importantes do consumidor e incorporá-las ao projeto do produto.

Como o mercado é cada vez mais dinâmico e o ciclo de vida do produto diminui continuamente, a equipe de projeto está sujeita a sofrer variações periódicas de comportamento, tornando-se fundamental a atualização rápida da informação sobre as novas necessidades do consumidor. A figura 4, elaborada a partir de informações obtidas na Alemanha (SOHLENIUS, 1992), indica uma tendência de que, para alguns segmentos de mercado (eletrônica e computadores), o desenvolvimento do projeto do produto deve melhorar e que nesse setor da empresa existe um espaço para buscar a vantagem competitiva. Esse espaço, representado pela região sombreada da figura 4 , apresenta um comportamento crescente com o tempo, indicando a evolução das exigências do consumidor e, conseqüentemente, a necessidade de aprimoramento na identificação destas exigências e na capacidade da empresa. 


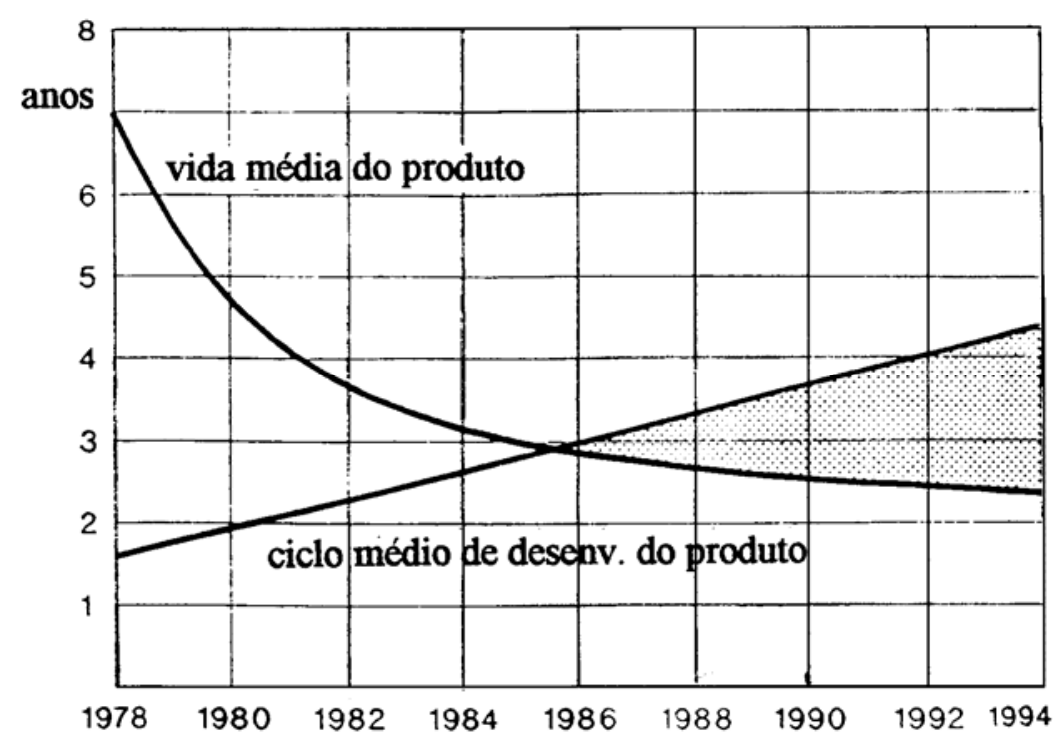

FIGURA 4 - Região de busca competitiva (SOHLENIUS, 1992)

\subsection{Comportamento do produto}

Como mencionado anteriormente, $\mathrm{o}$ consumidor avalia o produto por meio dos seus valores, considerando a interação com a empresa. Assim, o êxito ou o fracasso do projeto do produto repercutem significativamente na maneira pela qual a empresa irá se comportar no mercado a longo prazo e, conseqüentemente, no comportamento do produto. Vale dizer que a escolha estratégica do tipo de produto e a forma pela qual este é projetado irão determinar o seu comportamento no mercado e, conseqüentemente, a sua competitividade. Estão implícitos, neste procedimento, a qualidade, a produtividade e a complexidade relacionadas ao produto.

\subsection{Apoio tecnológico}

A mudança tecnológica dos últimos anos acirrou a competição. Na busca da vantagem competitiva, as empresas procuram apoio nas tecnologias disponíveis e em desenvolvimento, fundamentalmente para o projeto de novos produtos, mais atraentes em tempo reduzido, ou seja, com base na diferenciação.

Os sistemas computacionais com seus periféricos e programas aplicativos de recursos cada vez maiores, possibilitam um ambiente de trabalho amigável, produtivo, flexível e motivador.
Entretanto, a competitividade do produto não é conquistada apenas com pesquisa e desenvolvimento, mesmo com apoio de equipamentos e softwares sofisticados; é fundamental que a tecnologia seja usada no desenvolvimento de produtos de maneira que resulte no eficaz atendimento aos anseios do consumidor. Para que esse apoio proporcione efetivo suporte ao projeto do produto é necessária, sobretudo, organização consistente do ambiente de trabalho.

\subsection{Organização e gerenciamento}

A organização consistente para o desenvolvimento do projeto de produtos deve envolver a empresa como um todo, tanto em relação aos princípios e arquiteturas globais 
do sistema quanto no que se refere aos níveis de detalhamento do trabalho, considerando habilidades, estratégias de mercado e métodos de solução de problemas. Ganham, assim, importância as práticas de engenharia e os modelos de gerenciamento, sobretudo o gerenciamento do projeto do produto, que é fator determinante na competitividade. Visão, flexibilidade e resposta às necessidades do mercado são qualidades inerentes ao modelo de gerenciamento.
Por outro lado, a evolução das organizações consistentes, em que a Engenharia Concorrente está presente, aumenta a complexidade do processo de projeto e torna o gerenciamento mais complexo. Em contrapartida, surgem modelos de gerenciamento para solucionar o problema, como o que foi proposto por KUSIAK \& WANG (1993) baseado em algorítmo que considera a desvinculação de atividades interligadas e a seqüência dessas atividades, visando reduzir o tempo de projeto do produto.

\subsection{Meio ambiente e estética}

A dinâmica do comportamento humano gerou diferentes paradigmas ao longo dos anos, sob diversos pontos de vista. Particularmente no setor de projeto e manufatura estamos vivenciando o "Paradigma E", relacionado com a preocupação na preservação do meio ambiente. A figura 5 ilustra a evolução dos paradigmas.

Essa preocupação, atualmente, é motivo de competitividade que deve ser considerado no projeto do produto. É preciso, entretanto, ponderar entre os lucros a curto prazo e as implicações ambientais a longo prazo. Cada vez mais o consumidor tem consciência de que o produto deve ser nãopoluente e o projetista deve estar alerta para o que esta situação implica em termos de custo, desperdício e reprojeto.

Outro fator de significância na atualidade é o estilo de vida das pessoas, que influencia na competitividade do produto por meio da estética. Portanto, não é mais possível ignorar o aspecto visual no projeto do produto, devendo-se considerar que a vida estética do produto pode ser tão longa quanto a funcional.

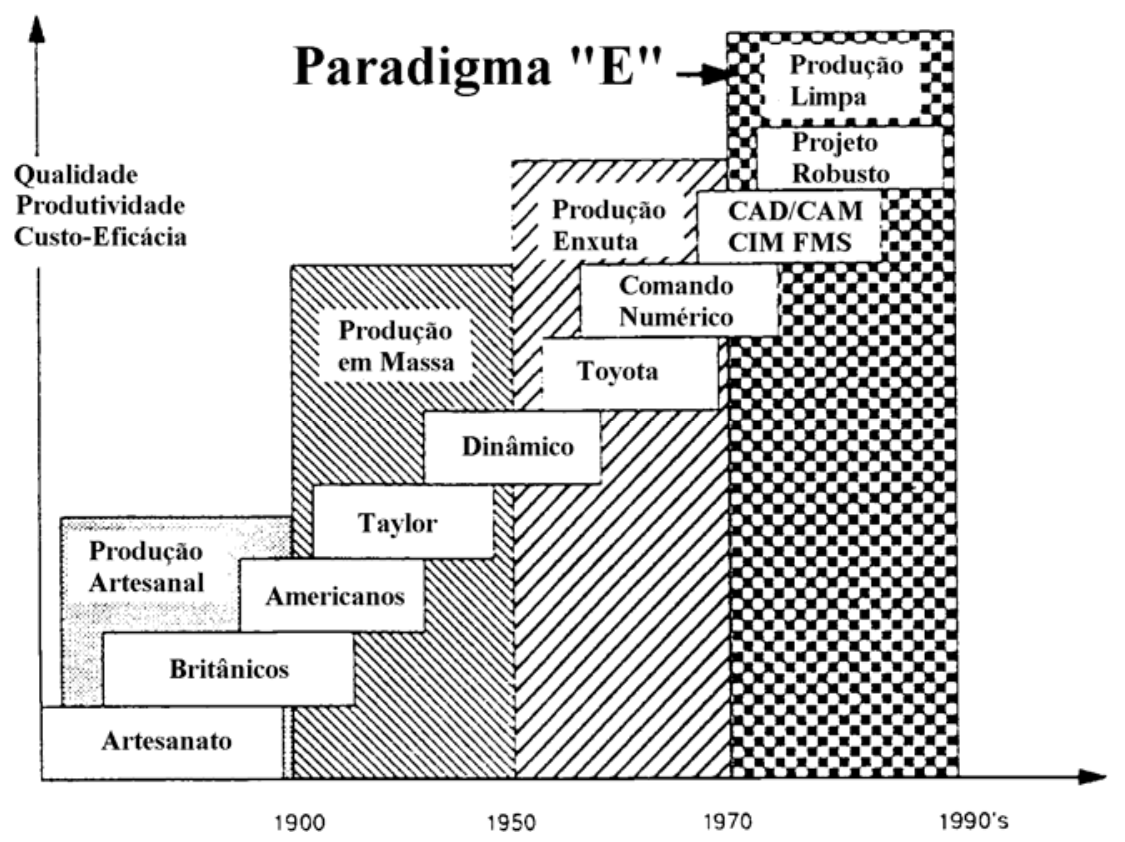

FIGURA 5 - Evolução dos paradigmas (TIPNIS, 1994) 
Deve-se ter em mente que em cada uma das diversas situações que levam à competitividade do projeto do produto há um requisito fundamental: a exigência de "ser bem feito", em todos os aspectos, ou seja, a qualidade é indispensável no projeto do produto e é regente da competitividade da empresa.

Segundo CLAUSING (1994), a diferença entre o êxito e o fracasso tem origem na receptividade das necessidades do cliente em relação ao produto, na viabilidade de conceitos consistentes, na viabilidade de execução do projeto, na robustez da função qualidade, na economia de produção, no sucesso da integração, na eficácia do reaproveitamento e no impacto estratégico. Temos, assim, vários fatores que levam à qualidade total.

\section{A Qualidade do Projeto do Produto na Competitividade \\ 3.1. Conceito de qualidade para o projeto do produto}

A qualidade do projeto do produto não é mais um fator isolado no ciclo de vida deste, mas é a qualidade sob todos os fatores que determinam a satisfação do consumidor.

A Sociedade Americana para o Controle da Qualidade (ASQC) adota a seguinte definição para qualidade (SME, 1987): "Qualidade é o conjunto de características de um produto ou serviço relacionado com a habilidade de satisfazer certas necessidades”. Esta definição é condizente com aquilo que se espera do projeto de um produto para a competitividade, pois neste aspecto estão as expectativas do cliente que comprou o produto, relacionadas com a função qualidade em todo o ciclo de vida deste; portanto, são considerados uso, manutenção, disponibilidade, serviços e instruções, entre outros.

A amplitude do tema qualidade sugere que, a exemplo da competitividade, é melhor sistematizar os fatores e procedimentos que levam à qualidade, no caso, do projeto do produto, do que adotar conceitos genéricos e abstratos.

\subsection{Fatores que incorporam qualidade}

A informação sobre as necessidades do consumidor é, talvez, o primeiro fator para qualificar o produto; é o meio pelo qual a engenharia de produtos pode incorporar os anseios do cliente no produto.

Um processo de projeto bem estruturado, com integração e flexibilidade e sob liderança responsável, produz um efeito benéfico significativo sobre os requisitos fundamentais para a competitividade, como baixo lead-time e alta produtividade, além da qualidade inerente ao produto.

Naturalmente que tanto o lead-time quanto a produtividade serão melhorados com ferramentas tecnologicamente atualizadas, como computadores, softwares aplicativos e metodologias de trabalho consagradas.
O conhecimento tecnológico da equipe de projeto do produto, sua habilidade para entender as necessidades do consumidor e de repassá-las para o produto, bem como a criatividade, são fatores de incorporação da qualidade nos primeiros estágios do projeto do produto.

A visão de negócio da gerência para captar necessidades de diferenciação no produto, de perceber novos estilos de vida e novos paradigmas em tempo hábil para que o produto seja lançado antes que o concorrente possa fazê-lo, caracteriza-se numa estratégia relevante. Um fator considerável é a capacidade de prever a qualidade do produto já na sua fase conceitual.

A consideração de preservar o meio ambiente é um fator qualitativo do projeto 
do produto, e pode-se dizer estratégico, com importância significativamente crescente, em âmbito mundial.

A forte competitividade mundial exige qualidade total no produto sendo que o projeto deve incorporar essa qualidade em todos os sentidos e prevê-la em todo o ciclo de vida do produto. Assim, fatores como a estética do produto passam a ser fundamentais.
Os princípios e a sistematização do trabalho da equipe são fundamentais para corretas especificações no projeto do produto; a qualidade para a competitividade também provém desse comportamento.

A equipe de projeto do produto deve levar em consideração a maneira pela qual o consumidor percebe a qualidade, seja técnica ou funcional. Algumas formas de percepção da qualidade pelo consumidor, segundo M RUP (1993), são: design, tecnologia de fabricação, distribuição, venda, assistência, disponibilidade e descarte.

\subsection{Quando incorporar qualidade ao projeto do produto}

Existem algumas considerações significativas para compreender que a fase de projeto conceitual é a mais representativa, no ciclo de desenvolvimento do produto, para que seja incorporada qualidade.

Inicialmente, os dados que podem ser observados na figura 6 (BART \& SCHNEBERGER, 1992) indicam que é vantajoso dedicar-se à qualificação do produto na fase de projeto, pois a maior parcela (70\%) dos custos do ciclo de vida do produto é reflexo somente da fase de projeto, em que é absorvido apenas 5\% do custo total de desenvolvimento do produto. Portanto, nessa fase o esforço de incorporar qualidade ao produto tem menor custo e, nessa razão, maior impacto competitivo.

É importante também incorporar qualidade nos primeiros estágios do projeto do produto, ou seja, na fase conceitual e, a rigor, quando os requisitos do projeto estão sendo discutidos. A importância desta colocação fica evidenciada pelo tempo de lançamento do produto, que admite uma redução de mais de $50 \%$ quando os problemas são identificados e resolvidos com certa antecedência, reduzindo os tempos de manufatura e de resposta às necessidades do consumidor e, portanto, gerando competitividade (BART \& SCHNEBERGER, 1992). Além disso é importante considerar e evitar o "efeito escala" do aumento do custo de alteração no produto em relação aos seus estágios de desenvolvimento (idéia, projeto, protótipo, produção e lançamento); o atraso na detecção de problemas representa um aumento do custo de alteração, que cresce em progressão geométrica de razão 10 (BART \& SCHNEBERGER, 1992).

Se for considerado que a qualidade total incorporada ao produto resulta em dividendos que superam a faixa de $200 \%$ - $600 \%$ (BART \& SCHNEBERGER, 1992), pode-se estimar que devem ocorrer reduções significativas de custos, melhoria funcional, enfim, maior satisfação do consumidor.

Cabe lembrar que, embora a preocupação com a qualidade deva ser maior na fase conceitual, nas demais fases do desenvolvimento do produto também é necessário agregar qualidade para que a empresa se mantenha competitiva; também não se deve esquecer que a melhor maneira de medir a qualidade é verificar o grau de satisfação do consumidor. 


\section{\% de Influência nos Custos Totais do Ciclo de Vida}

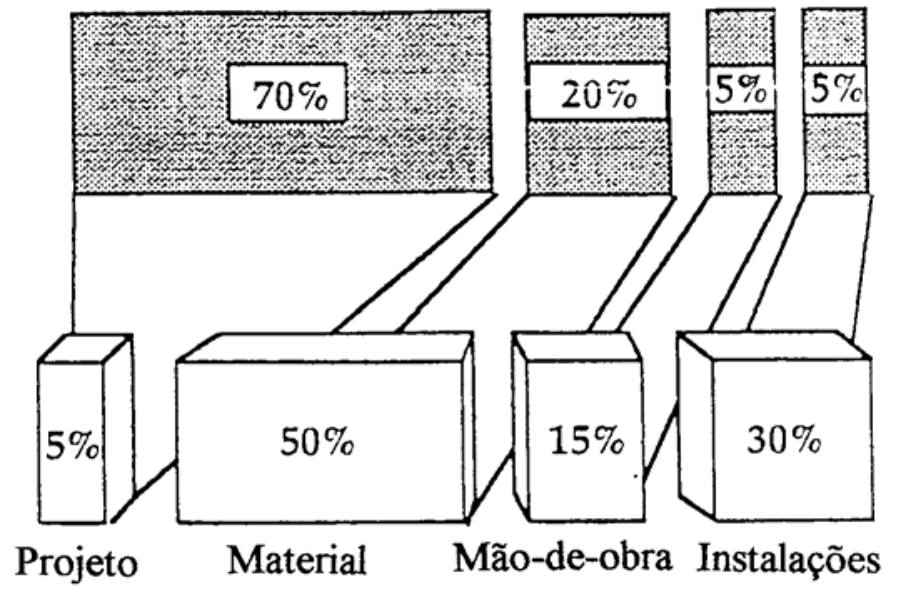

\% do Custo do Produto

FIGURA 6 - Influência do custo de desenvolvimento do produto sobre os custos do seu ciclo de vida

\section{Procedimentos para Agregar Qualidade ao Projeto do Produto}

A ntes de abordar os procedimentos isoladamente, ressalta-se o aspecto da conscientização de agregar qualidade por parte de toda a equipe de projeto, independentemente da função que cada pessoa deva executar. A consciên- cia de qualidade do produto deve ser inerente ao cumprimento da função dos projetistas, sem imposição, e originária de treinamento e filosofia de trabalho de cada empresa; a concepção para a qualidade deve ser assimilada por toda a equipe.

\subsection{Requisitos do projeto}

Como foi salientado anteriormente, um produto será competitivo se, fundamentalmente, satisfizer as necessidades dos consumidores. Parte-se então do princípio de que o consumidor deve ser ouvido e que seus anseios devem ser repassados ao produto. Assim, tem-se na definição dos requisitos um meio relevante de qualificar o produto e, então, atingir níveis satisfatórios de competitividade. Porém, antes dessa tarefa, é necessário ter, basicamentemente, dois cuidados: manter uma interface de comunicação com o consumidor e possuir habilidade para transformar as informações em características do produto; o primeiro cuidado é de competência predominantemente do pessoal de marketing, e o segundo compete preferencialmente aos projetistas.

\subsection{Interface com o consumidor}

Para entender as necessidades do consumidor, e então transformá-las em requisitos de projeto, a empresa deve ter um sistema de informação que "alimente" a equipe de projeto com dados relevantes para 0 produto. CLARK (1991) apresenta um modelo de fluxo de informações no ciclo de vida do produto, conforme mostrado na figura 7. 


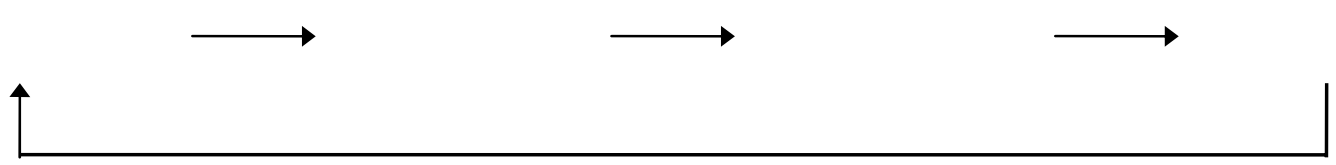

\section{FIGURA 7 - Sistema de informações no ciclo do produto}

Entretanto, o pessoal responsável pela coleta de informações deve estar habilitado para tal, o que significa conhecer profundamente o produto ou os recursos para projetar um produto. O ideal é que os responsáveis pelo projeto do produto (p. ex. engenheiros de projetos e de processos) executem essa função de interface com o consumidor.
Segundo M RUP (1993), a qualidade não consegue ser alcançada considerando-se individualmente o produto ou o consumidor, mas sim a interação de ambos em todas as fases da vida do produto. A rigor, o fluxo de informações deve ser considerado em relação a clientes interno, intermediários e externos.

\subsection{Habilidade da equipe}

A habilidade da equipe está relacionada à capacidade de incorporar no produto, de maneira eficaz, as necessidades do consumidor. Para isso a equipe necessita : formacão básica adequada e com conhecimento científico, dominar atividades de pesquisa e desenvolvimento, ter afinidade com descobertas científicas, possuir experiência em projeto de produtos e desenvolver pensamento analógico e de síntese. A habilidade exclusivamente de solucionar problemas, por mais aprimorada que seja, não é suficiente.

No entanto, o panorama atual quanto a habilidade das equipes nas empresas em geral é precário. Uma investigação feita em 1992 por ANDERSSON (1993) em empresas suecas, revelou que nenhum gerente estava familiarizado com métodos de projetos e processos disponíveis na literatura, ou outros propostos por pesquisadores. Segundo PHADKE (1989), a melhoria da qualidade por meio do projeto conceitual necessita de descoberta científica. De acordo com JASANY (1994), poucos fabricantes americanos acreditam que as Universidades possam ensinar o know-how da manufatura, e o sentimento é que este conhecimento provém da experiência. Considerando realísticas as informações acima, isso caracteriza uma equipe despreparada para um ambiente de Engenharia Concorrente.

Sobre o tema de educação na Engenharia de Projetos encontram-se trabalhos desenvolvidos no sentido de propor ações para sua melhoria (RABINS et al.,1986), ou de estudar e delinear princípios que deveriam ser estudados e pesquisados nas escolas (DIXON, 1991), além de discussões sobre o papel das Universidades e das empresas na educação de Engenharia de Projetos (DINSDALE, 1991). Este contexto revela a carência de conhecimento das equipes de projetos de uma maneira geral.

\subsection{Engenharia Concorrente}

O desenvolvimento do produto envolve vários setores funcionais de uma empresa e muitas pessoas, sendo que os setores de projeto e manufatura devem estar muito bem integrados a este modelo. É a Engenharia
Concorrente, que existe em decorrência da competitividade internacional e da evolução tecnológica associada à evolução do comportamento humano.

A Engenharia Concorrente agrega quali- 
dade ao produto mediante o aumento de produtividade, minimização de desperdícios e, de maneira geral, reduz tempos e custos de manufatura, atendendo melhor às necessidades dos consumidores. As melhorias nos projetos dos produtos podem ser feitas nos estágios iniciais do desenvolvimento, o que, como mencionado anteriormente, é muito significativo. A equipe de projeto tem condições de avaliar e discutir os problemas potenciais, evidentemente antes que eles ocorram, dando tempo suficiente para gerar novas alternativas. No entanto, para que a Engenharia Concorrente tenha êxito, deve estar baseada em teorias relevantes, ferramentas eficazes e gerenciamento dedicado. Este último requisito ganha importância em função da complexidade do processo de projeto que a Engenharia Concorrente proporciona.

É preciso estar ciente de que a Engenharia Concorrente exige definições claras de projeto, verificação de resultados em vários estágios de desenvolvimento do produto e responsabilidade total com liderança.

Alguns resultados da aplicação da Engenharia Concorrente mostram a sua importância no projeto do produto, como por exemplo, reduções de $20 \%$ a $70 \%$ no tempo de desenvolvimento do produto, aumentos de $20 \%$ a $100 \%$ na produtividade e aumento nas vendas, em empresas européias (BLAU, 1994); reduções no desenvolvimento de chaves elétricas, de 4 anos para 10 meses em lead-time, e de 30 dias para 3 dias para manufatura (SOHLENIUS, 1992).

\subsection{Metodologias e ferramentas}

Um projeto metódico é essencial para a qualidade do produto e para isso é importante a troca de informações tecnológicas e metodológicas entre os membros da equipe. Os recursos das modernas tecnologias, principalmente com o uso do computador e de métodos formalizados, constituem um poderoso apoio à qualidade do projeto do produto. São vários os métodos e ferramentas disponíveis que podem ser usados apropriadamente conforme as necessidades, podendo ser destacados os seguintes: QFD, FMEA, DFA, Taguchi, Análise de Valores, CAE/CAD/CAM e outros softwares de análise e simulação.

\subsection{Projeto robusto}

O projeto deve ser concebido para que a qualidade seja melhorada, minimizando as diferenças entre o previsto e o realizável. Neste sentido é importante ter-se um modelo de engenharia de projeto sistemático e bem estruturado, de maneira a reduzir a probabilidade de erros e, então, aumentar a produtividade e diminuir custos e tempo de desenvolvimento ( lead-time ).

Para assegurar a robustez do projeto é necessário ter um indicador do efeito das alterações de parâmetros na performance do produto, bem como dispor de um meio eficaz de informações desses efeitos em todo o ciclo de vida do produto. Para estimar a robustez do projeto, sob este ponto de vista, PHADKE (1989) indica dois métodos: a "razão sinal/ruído" que mede a qualidade e os "arranjos ortogonais" usados para o estudo de muitos parâmetros simultaneamente.

\subsection{Projeto para o descarte}

O Paradigma "E” não está mais restrito 
estratégicos das empresas de vários setores importantes, como o de eletrônica e o automobilístico. Considerando o ciclo de vida do produto, é preciso sobretudo ter consciência dos riscos que corre a sociedade do futuro.

Assim sendo, as empresas devem passar a adotar procedimentos para melhorar a qualidade do projeto do produto com a preocupação permanente do meio ambiente. Entre estes procedimentos, destacam-se os seguintes: responsabilidade total da empresa em todo o ciclo de vida do produto sobre riscos ao meio ambiente, reprojetar produtos, proteger os usuários, os trabalhadores, a comunidade e o ecossistema contra efeitos danosos que o produto possa ter, desenvolver produtos prevendo-os não-poluentes e recicláveis, informar os consumidores por meio de manuais e outros avisos bem visíveis sobre o correto uso e descarte do produto.

Uma preocupação constante que a equipe de projeto deve ter, notadamente quanto a reciclagem de produtos, é a especificação de materiais facilmente separáveis e, mais importante, a adoção de materiais compatíveis.

\subsection{Outros procedimentos}

A estética do produto é um fator a ser considerado pela equipe de projetos. Considerando que a aparência de um produto pode ser analisada sob três aspectos de satisfação estética (sensorial, formal e simbólica), cada uma podendo ser desdobrada em vários aspectos (REDMOND, 1993), a equipe de projeto deve desenvolver a capacidade de observar, perceber, imaginar e criar concepções que atendam aos anseios dos consumidores. Assim, a equipe, trabalhando integrada e tendo estas preocupações pode conceber produtos que atendam a faixas amplas de mercado. Porém, a preocupação com a estética não deve interferir nos aspectos funcionais, de manufatura e de uso do produto.
A criatividade da equipe pode significar a diferença competitiva necessária quando os competidores estão nivelados quanto a todos os outros aspectos; cabe ressaltar que a competitividade internacional leva a essa situação. A criatividade deve estar presente em todo o ciclo de vida do produto (incluindo gerenciamento, marketing, vendas, manufatura, etc.), mas é na fase de projeto conceitual que ela mais se evidencia e se faz necessária. Como procedimento para incorporar qualidade ao projeto do produto com base na criatividade estão disponíveis diversas técnicas, dentre as quais destacamse (BACK, 1983): Brainstorming, Método da Inversão, Analogia, Sinergia, Caixa Preta e Método Morfológico.

\subsection{Eliminação de barreiras à mudança}

A qualidade do projeto do produto não será satisfatória se a equipe de projeto conviver com barreiras às mudanças. RINGLEIN (1994) aponta seis barreiras à modificação do processo de desenvolvimento do produto: estagnação, deficiência de interpretação, resistência à mudança, falta de responsabilidade, inveja e conflitos quanto a recursos.

A estagnação em uma empresa pode ser eliminada com uma mudança imperativa, considerando os concorrentes, as expectativas dos consumidores e o ambiente futuro.
Outra maneira para eliminar a estagnação é ter liderança atuante e dinâmica na equipe de projeto, que oriente as atividades para o contínuo desenvolvimento e aprimoramento.

A deficiência de interpretação, significando o erro de entendimento ou interpretação de informações, pode ser eliminada com constantes comunicações no ambiente de projeto, fazendo-se uso de conferências, reuniões, filmes, comunicados verbais e outros meios de comunicação.

A resistência à mudança nos componentes da equipe pode ser eliminada principal- 
mente pelo convencimento de que a mudança proposta será interessante e benéfica para todos. Para isso são necessárias constantes explicações, instruções, meios motivadores e demonstrações.

A falta de responsabilidade ocorre quando a pessoa se isenta de qualquer atribuição, delegando atividades a outros. Para eliminála, a melhor maneira é exigir que a pessoa expresse seus compromissos abertamente, perante seus colegas, subordinados e superiores.

A inveja e a mentira podem ser evitadas mediante um planejamento antecipado para prevenir controvérsias relacionadas a problemas de personalidade. Outro procedimento é evitar longos períodos sem comunicação na equipe, o que pode ser conseguido com informativos mensais ou semanais.

Os conflitos que surgem quando novos recursos de projeto são necessários para atender o mercado podem ser eliminados das seguintes maneiras: concentrar esforços em determinadas características do projeto, sub-contratar serviços, eliminar características que agregam baixo valor ao produto, unir esforços com concorrentes, aumentar a eficiência da engenharia e redefinir prioridades para projetos insignificantes.

O somatório de procedimentos corretos certamente resulta na agregação de qualidade ao projeto do produto e, então, é fator decisivo para a competitividade da empresa.

\section{Conclusões}

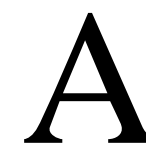

o setor de projeto de produtos cabe uma responsabilidade vital para a empresa, pois dali partem os fundamentos que irão definir o seu êxito ou fracasso, com base na qualidade para a competitividade. A missão não é fácil, uma vez que é grande a quantidade e diversidade de fatores a serem considerados para alcançar o êxito. É oportuno então sistematizar os fatores influentes e adotar procedimentos que somem qualidade ao produto nas suas mais diversas maneiras, tendo sempre em mente que a qualidade do produto passa por todos os estágios do seu ciclo de vida. Este é o aspecto fundamental que estabelece o elo de dependência entre a qualidade do projeto do produto e a competitividade.

A definição do desenvolvimento de um produto é feita com base no seu modelo, na linha de atuação de cada empresa e no supersistema no qual ela está inserida. Portanto, não se pode propor uma "receita" em que estejam listados todos os procedimentos necessários para que um determinado projeto de produto seja executado de forma a garantir competitividade para a empresa. O melhor conjunto de procedimentos é específico de cada caso e precisa ser analisado criteriosamente, pois vários deles estão disponíveis, abrangendo áreas tecnológicas, humanas, gerenciais, etc., mas somente agregarão valor se forem corretamente utilizados. Esses procedimentos e suas relações com a qualidade do projeto do produto para a competitividade estão delineados neste trabalho para que possam servir de orientação às empresas envolvidadas em um ambiente tão nebuloso que torna difícil visualizar os caminhos para a competitividade.

Com a evolução do comportamento humano e as mudanças tecnológicas, os consumidores passaram a ser impositores dos requisitos do projeto dos produtos, e com exigência crescente. Cabe, agora, às empresas a preocupação com fatores organizacionais, comportamentais e de integração, e não apenas com fatores técnicos.

A fase conceitual do projeto do produto é o foco de concentração dos esforços para agregar qualidade ao produto, pois as mudanças que se fizerem necessárias após essa fase muito provavelmente tornarão inviável o produto no mercado. Portanto, é necessário agregar qualidade em todos os aspectos quando o projeto está na fase conceitual. 
Os procedimentos para agregar qualidade ao produto visando a competitividade, depois de sistematizados, necessitam de gerenciamento eficaz, pois são muito dependentes do comportamento das pessoas da equipe; as barreiras que surgem no desenvolvimento do produto são predominantemente de caráter humano.

\section{Agradecimentos}

O autor registra aqui o seu agradecimento à Profa. Dra. Ingeborg Sell pela análise crítica feita a este trabalho.

\section{Referências Bibliográficas:}

ALVES FILHO, A.G., PIRES, S.R.I., \& VANALLE, R.M.: "Sobre as Prioridades Competitivas: Compatibilidades e Seqüências de Implementação”. Gestão \& Produção, v.2, n.2, p.173-180, agosto 1995.

ANDERSSON, P.: "Design for Quality - As Perceived by Industry”. Proceedings ICED ‘ 93, p 843-848, The Hague, August 1993.

BACK, N.: Metodologia de Projeto de Produtos Industriais. Guanabara Dois, Rio de Janeiro, 1983.

BART, H. \& SCHNEBERGER, D.: Design for Competitiveness. Institute for Competitive Design, 1992.

BLAU, J.R.: "Europe Turns Competitive with Concurrent Engineering”. Machine Design, v.66, n.11, p 41-44, June 1994.

CLAUSING, D.P.: “Total Quality Development”. Mechanical Engineering, v.116, n.3, p.94-96, March 1994.

CLARK, K.B. \& FUJIMOTO, T.: Product Development Performance. Harvard Business Schol Press, Boston, 1991.

DINSDALE, J.: “Engineering, Design Education”. Annals of the CIRP, v.40/2, p.595-601, 1991.

DIXON, J.R.: “New Goals for Engineering Education”. Mechanical Engineering, v.113, n.3, March, 1991.

HARTLEY, J.R.: Concurrent Engineering. Productivity Press, Cambridge, 1992.
JASANY, L.: "Setting Designers Straight”. Machine Design, v.66, n.23, December, 1994.

KUSIAK, A. \& WANG, J.: "Efficient Organizing of Design Activities”. International Journal of Production Research, v.31, n.4, p 753-769, 1993.

M RUP, M.: “Total Life Models - an Important Tool in Design for Quality”. Proceedings ICED ' 93, p 849-857, The Hague, August 1993.

PHADKE, M.S.:Quality Engineering Using Robust Design. Prentice Hall, New Jersey, 1989.

RABINS, M., FENVES, S., SEIREG, A., NADLER,G., RICHARDSON,H., CLARK,H.: "Design, Theory and Methodology - A New Discipline”. Mechanical Engineering, v.108, n.8, August, 1986.

REDMOND, J.: "New Product Appearance in Relation to Market Response”. Proceedings ICED ' 93, p 1205-1212, The Hague, August 1993.

RINGLEIN, J.: "Breaking the Barriers to Change". Machine Design, v.66, n.5, March, 1994.

SME:. Assurance and Control of Quality. Tool and Manufacturing Engineers Handbook, v.IV, 1987.

SOHLENIUS, G.: “Concurrent Engineering”. Annals of the CIRP, v.41/2, p.645-655, 1992.

TIPNIS, V.A.: "Challenges in Product Strategy, Product Planning and Technology Development for Product Life Cycle Design”. Annals of the CIRP, v.43/1, p 157-162, 1994.

\section{FACTORS AND PROCEDURES TO DETERMINE QUALITY IN PRODUCT DESIGN FOR COMPETITIVITY}

\section{Abstract}

The influence of the design quality on product competitivity takes place throughout the stages of its life-cycle. This work deals with a systematic approach in order to relate the 
product design quality to enterprise competitivity by means of the influential factors in that relation, seeking to emphasize its importance. The different ways available to aggregate quality are discussed aiming to orientate the teamwork organization in product design environments. The conceptual phase of the product design is emphasized as the focus of the efforts to qualify the product.

Key-words: product design, quality, competitivity. 